\title{
Electronic Personal Health Record
}

National Cancer Institute

\section{Source}

National Cancer Institute. Electronic Personal Health Record. NCI Thesaurus. Code C142530.

A computer application that is used by patients to access, manage, and share their digitally represented health information in a private, secure, and confidential environment. 